\title{
Las medidas de mejora regulatoria como instrumento en la lucha contra la despoblación del medio rural en Galicia
}

\author{
Luis Míguez Macho*1 \\ Universidade de Santiago de Compostela - Facultade de Dereito
}

Recibido: 15 de mayo de 2020 / Aceptado: 1 de julio de 2020

\begin{abstract}
Resumen
El objeto de este trabajo es el análisis de diversas medidas de mejora regulatoria, introducidas por la Comunidad Autónoma de Galicia a lo largo de la última década, que pueden ayudar a mitigar la despoblación del medio rural, al facilitar la implantación de actividades productivas en las zonas en riesgo de despoblación y contribuir, así, a la fijación de población en ellas. Ello incluye el estudio del nuevo régimen urbanístico y de intervención administrativa en las actividades económicas en el medio rural, así como de la aparición, al lado de la política tradicional de reestructuración de la propiedad agraria, de otra política pública orientada a la recuperación y puesta en valor de la tierra productiva en estado de abandono o de cultivo deficiente.

Palabras clave

Despoblación / Medio rural / Mejora regulatoria / Movilidad de tierras.

\section{Regulatory improvement measures as an instrument in the fight against rural depopulation in Galicia}

\section{Abstract}

The aim of this paper is the analysis of various regulatory improvement measures introduced in the autonomous region of Galicia over the last decade to help mitigate the depopulation of the rural areas by facilitating the establishment of productive activities in areas at risk of depopulation and thus contributing to increasing and maintaining the population there. It includes the study of the new regime of administrative intervention in economic activities in the rural areas, as well as the emergence, together with the traditional policy of restructuring agricultural property, of another public policy aimed at recovering and enhancing the value of productive land which, at the time, is abandoned or under deficient cultivation.

\section{Keywords}

Depopulation / Rural areas / Regulatory improvement / Land mobility.

JEL Codes: J19, K23, Q15, R52.

\section{Introducción}

La Exposición de Motivos del pionero proyecto de Ley de impulso demográfico de Galicia (que no ha podido concluir su tramitación parlamentaria por la disolución anticipada del Parlamento de Galicia producida en febrero de 2020)2 ${ }^{2}$, después de explicar en su apartado I las causas del actual proceso de disminución de la natalidad y consecuente envejecimiento y descenso de la población en la Comunidad

*Correspondencia autor: luis.miguez@usc.es

1 Proyecto de investigación Instrumentos jurídicos para la lucha contra la despoblación en el ámbito rural (DESPORU), ref. RTI2018-099804-A-100, financiado por FEDER/Ministerio de Ciencia, Innovación y Universidades, Agencia Estatal de Investigación, Gobierno de España.

2 El texto del proyecto puede consultarse en https://transparencia.xunta.gal/tema/informacion-de-relevanciaxuridica/normativa-en-tramitacion/aprobada-e-publicada-no-dog/-/nt/0401/anteproxecto-lei-impulso-demografico-galicia. Última consulta el 4 de mayo de 2020. 
Autónoma, señala también incidentalmente que "a esta compleja situación se añade un reparto de la población en el territorio que tiende cada vez más a concentrarse en las provincias occidentales, en las mayores áreas urbanas y en los ayuntamientos litorales". La consulta de la evolución de la población gallega desde el censo de 1981 hasta el padrón municipal de 2019 corrobora que, tras la implantación del autogobierno en Galicia, hay comarcas rurales, casi todas de interior, que han perdido más de la mitad de su población ${ }^{3}$, por lo que las políticas públicas de la actual etapa democrática y autonómica no han servido para atenuar dicha tendencia, aunque se haya incrementado la dotación de infraestructuras y servicios de todo tipo en esas zonas, lo que incluye, en particular, la mejora de las vías de comunicación.

Por consiguiente, Galicia, como las demás comunidades autónomas afectadas por el problema de la despoblación del medio rural, no solo necesita diseñar y aplicar políticas públicas efectivas de impulso demográfico, que es a lo que va dirigido el mencionado proyecto de ley, sino también de equilibrio demográfico territorial y dinamización rural. De otra forma, se corre el riesgo de que, si tuviesen éxito las políticas de impulso demográfico, pero se mantuviese la actual tendencia de asentamiento de la población en las zonas urbanas y costeras, el problema de la despoblación del medio rural y del interior se podría agravar ulteriormente.

No parece necesario extenderse acerca de los perjuicios que supone la despoblación del medio rural. Además de las consecuencias sobre el patrimonio cultural, etnográfico y arquitectónico de las zonas que se quedan sin población, hay también graves repercusiones ambientales, como las expuestas en el Dictamen de la Comisión Especial no Permanente del Parlamento de Galicia de estudio y análisis de las reformas de la política forestal, de la prevención y extinción de incendios forestales y del plan forestal de Galicia, aprobado el 31 de julio de 2018, en el que se evalúa la experiencia acumulada desde 2006 y, específicamente, la extraordinaria ola de incendios que sufrió Galicia en octubre de 20174. Este documento analiza con detalle, en sus apartados 3.3.3.1 y 3.3.3.2, los procesos de desagrarización y de envejecimiento y pérdida de población en el medio rural, que provocan el abandono de la tierra agraria productiva y al que sigue la extensión desordenada de la vegetación y del bosque, que, a su vez, es una de las principales causas del aumento del peligro de los incendios forestales.

La implantación de actividades productivas en el medio rural es uno de los factores que podrían contribuir a mitigar la despoblación, al ofrecer a los residentes en esas áreas oportunidades de ocupación in situ y, probablemente, atraer nueva población, tal y como señalan Bustillo Bolado y Menéndez Sebastián (2005, p. 114 y ss.). Tal implantación depende de circunstancias muy diversas, pero, desde el punto vista jurídico, presentan especial interés, por la incidencia positiva que pueden tener, las modificaciones legislativas emprendidas por la Comunidad Autónoma de Galicia en la última década con el fin de favorecer el emprendimiento y el desarrollo de iniciativas empresariales. El presente estudio analiza esas tendencias legislativas de mejora regulatoria dividiéndolas en dos partes.

Por un lado, estaría el nuevo régimen urbanístico y de intervención administrativa en las actividades económicas en el medio rural. En este punto se abordan las novedades en materia de uso del suelo para actividades productivas en el medio rural introducidas por la Ley 2/2016, de 10 de febrero, del suelo de Galicia, así como la definitiva eliminación, mediante la Ley 9/2013, de 19 de diciembre, del emprendimiento y de la competitividad económica de Galicia, del requisito de la licencia municipal previa para la apertura o el funcionamiento de las actividades económicas que se realizan en estable-

\footnotetext{
${ }^{3}$ La población total de Galicia ha disminuido ligeramente en ese período (de 2.811 .912 a 2.699 .499 habitantes), pero, en la provincia de Lugo, la comarca de Ancares ha pasado de 21.407 a 9.873 habitantes, la de Chantada de 21.367 a 13.141, la de Fonsagrada de 12.557 a 4.921, la de Meira de 8.974 a 5.125 y la de Quiroga de 10.197 a 5.178. Más dramático aún es el caso de la provincia de Ourense, donde A Baixa Limia ha pasado de 19.112 a 6.676 habitantes, A Limia de 41.480 a 20.075 , 0 Ribeiro de 31.382 a 15.808, Terra de Caldelas de 9.794 a 2.789, Terra de Celanova de 38.907 a 17.497, Terra de Trives de 11.240 a 3.924 y la comarca de Viana de 12.336 a 5.682. En cambio, en la provincia de A Coruña, un descenso de la población proporcionalmente tan fuerte solo se aprecia en la comarca de Ortegal, que ha pasado de 21.614 a 11.978 habitantes, y en la de Pontevedra, en la comarca de Paradanta, que ha pasado de 25.083 a 12.168 habitantes. Los datos están tomados del Instituto Galego de Estatística, que se basa en los del censo (para 1981) y en los del padrón municipal (para 2019) que publica el Instituto Nacional de Estadística.
}

${ }^{4}$ Boletín Oficial del Parlamento de Galicia, X legislatura, núm. 346, de 10 de agosto de 2018. 
cimientos o instalaciones permanentes. Asimismo, serán objeto de estudio las previsiones de la Ley 5/2017, de 19 de octubre, de fomento de la implantación de iniciativas empresariales en Galicia, con especial atención al régimen de autorización única que establece para los aprovechamientos forestales, de tanta importancia en el medio rural gallego.

Por otro lado, en el ámbito de la ordenación de la actividad agraria, destaca la aparición, al lado de la política tradicional de reestructuración de la propiedad agraria, de otra política pública orientada a la recuperación y puesta en valor de la tierra productiva, aún carente de tratamiento en la literatura científica, a pesar de que el principal problema al que se enfrenta el agro gallego en la actualidad ya no es solo el minifundismo, sino, sobre todo, el abandono de la tierra.

\section{El nuevo régimen urbanístico y de intervención administrativa en las actividades económicas en el medio rural}

\subsection{La simplificación del régimen urbanístico de los usos productivos del suelo admisibles en el medio rural}

La Ley del suelo de Galicia de 2016 ha simplificado considerablemente el régimen urbanístico aplicable a la implantación de actividades productivas en el medio rural y, en especial, en el suelo clasificado como rústico, en relación con las previsiones de la anterior Ley 9/2002, de 30 de diciembre, de ordenación urbanística y protección del medio rural de Galicia, que, con todo, también se habían ido suavizando en las diferentes modificaciones que esta experimentó durante su período de vigencia.

En el suelo de núcleo rural, como destaca Valenzuela Rodríguez (2019, pp. 223-224), la Ley del suelo de Galicia de 2016 opta por remitir al plan urbanístico la concreción de los usos admisibles, dentro del marco general que establecen sus artículos 25 y 26, así como los correlativos artículos 39 y 40 del reglamento de la ley, aprobado por el Decreto 213/2016, de 9 de noviembre. Ese marco general parte de que, como en la legislación anterior, el uso característico de las edificaciones en los núcleos rurales es el residencial, pero, precisamente para favorecer el asentamiento de población en aquellos, han sido considerados como complementarios de ese uso residencial, y por lo tanto admisibles, los usos terciarios o productivos, las actividades turísticas y artesanales, los pequeños talleres, invernaderos y equipamientos, y aquellos otros que guarden relación directa con los tradicionalmente ligados al asentamiento rural de que se trate o que den respuesta a las necesidades de la población residente en ellos. En todo caso, quedan prohibidas las naves industriales y las nuevas instalaciones destinadas a la producción ganadera, salvo las pequeñas construcciones artesanales o para el autoconsumo ${ }^{5}$.

Añade el Reglamento de la Ley del suelo de Galicia que el carácter complementario de esos usos y sus condiciones serán definidos por el plan general para cada ordenanza que se establezca en el suelo de núcleo rural (artículo 39.2, párrafo segundo). Sin embargo, esto no es exacto, ya que en los municipios de menos de 5.000 habitantes puede no existir plan general de ordenación, sino el plan básico municipal previsto en el artículo 63 de la Ley del suelo de Galicia que, a su vez, desarrolla el plan básico autonómico al que se refiere el artículo 49 de esta [instrumentos ambos analizados en Míguez Macho $(2019 \text {, p. } 337 \text { y ss. y p. } 340 \text { y ss.)] }]^{6}$. En tal caso, la previsión de los usos complementarios admisibles en el suelo de núcleo rural se encontrará en las ordenanzas tipo del plan básico autonómico que asuma cada plan básico municipal.

Con todo, el cambio más importante es el que afecta al suelo rústico. Frente al complejo sistema de determinación de usos y actividades permitidas, autorizables y prohibidas que establecía la derogada

\footnotetext{
${ }^{5}$ Aclara el artículo 40.1 del Reglamento de la Ley del suelo de Galicia que, a estos efectos, no tienen la consideración de naves industriales las pequeñas construcciones relacionadas con las actividades complementarias de primera transformación, almacenamiento y envasado de productos del sector primario, y que se entiende por pequeñas construcciones artesanales o de autoconsumo aquellas explotaciones ganaderas que figuran así definidas en la normativa sectorial correspondiente.

${ }^{6}$ El Plan básico autonómico de Galicia ha sido aprobado por el Decreto 83/2018, de 26 de julio.
} 
Ley de ordenación urbanística y protección del medio rural de Galicia de 2002, la ley vigente se limita a enunciar los usos y actividades admisibles (artículo 35.1), y añade a continuación el régimen urbanístico para su realización (artículo 36), tal y como se expone en Raposo Arceo (2019, p. 252 y ss). A los efectos de este estudio, interesa destacar los usos y actividades más directamente relacionados con la implantación de actividades productivas en el medido rural, que serían los siguientes: las construcciones e instalaciones agrícolas en general; las construcciones e instalaciones destinadas al apoyo de la ganadería extensiva e intensiva y de las instalaciones apícolas; las construcciones e instalaciones forestales destinadas a la gestión forestal y las de apoyo a la explotación forestal, así como las de defensa forestal, talleres, garajes y parques de maquinaria forestal; las construcciones e instalaciones destinadas a establecimientos de acuicultura; las actividades e instalaciones comprendidas en el ámbito de la legislación minera, incluidos los establecimientos de beneficio; las pirotecnias; las instalaciones vinculadas funcionalmente a las carreteras y previstas en la ordenación sectorial de estas, así como las estaciones de servicio; las instalaciones e infraestructuras hidráulicas, de telecomunicaciones, producción y transporte de energía, gas, abastecimiento de agua, saneamiento y gestión y tratamiento de residuos; las construcciones de naturaleza artesanal o de reducida dimensión que alberguen actividades complementarias de primera transformación, almacenamiento y envasado de productos del sector primario; las construcciones y rehabilitaciones destinadas al turismo que sean potenciadoras del medio donde se sitúen; y las construcciones e instalaciones para equipamientos y dotaciones públicos o privados?.

Que esas actividades se puedan realizar, efectivamente, en el suelo rústico depende de varios factores, que desarrolla Raposo Arceo (2019, p. 263 y ss.). En primer lugar, de los instrumentos de ordenación del territorio, que pueden incluir como determinaciones vinculantes la exclusión en ciertas zonas de algunos usos del suelo inicialmente admisibles. En la actualidad, en Galicia solo hay dos instrumentos generales de ese tipo en vigor: las Directrices de ordenación del territorio, aprobadas por el Decreto $19 / 2011$, de 10 de febrero, y el Plan de ordenación del litoral, aprobado por el Decreto 20/2011, de 10 de febrero, y únicamente este último contiene determinaciones que excluyen usos en ciertas zonas. En segundo lugar, cuando se trata de suelo rústico de especial protección, tendrán que respetarse las previsiones de la legislación sectorial aplicable a la categoría de suelo de que se trate, y deberá obtenerse la autorización o informe favorable del órgano administrativo competente. En tercer lugar, para las construcciones de naturaleza artesanal o de reducida dimensión que alberguen actividades complementarias de primera transformación, almacenamiento y envasado de productos del sector primario, hace falta una autorización del órgano de la Administración autonómica competente en materia de urbanismo ${ }^{8}$. Por último, para las construcciones y rehabilitaciones destinadas al turismo, que sean potenciadoras del medio donde se sitúen, y para las construcciones e instalaciones para equipamientos y dotaciones públicos o privados, se requiere la aprobación de un plan especial de infraestructuras y dotaciones, salvo que se puedan acoger a lo previsto en el artículo 40 de la ley en relación con las edificaciones existentes de carácter tradicional.

Este último precepto es de gran trascendencia práctica tanto para el uso residencial como para la implantación de usos productivos en el medio rural, porque permite que las edificaciones tradicionales existentes en suelo de núcleo rural y en suelo rústico se puedan destinar a usos residenciales, terciarios o productivos, a actividades turísticas o artesanales y a pequeños talleres y equipamientos, siendo posible su reforma, rehabilitación y reconstrucción (excepto el límite de altura) sin necesidad de cumplir los parámetros urbanísticos aplicables, y también su ampliación, incluso en volumen independiente, siempre que esta no supere el cincuenta por ciento del volumen originario de la edificación. Además, el concepto de edificación tradicional que se utiliza es muy amplio, al no exigirse que la edifica-

\footnotetext{
7 Esta lista ha sido ampliada por el artículo 50.1 del Reglamento de la ley añadiendo las construcciones e instalaciones que presten servicios necesarios o convenientes para la utilización y disfrute del dominio público marítimo-terrestre.

${ }^{8}$ Lo mismo se prevé para las construcciones destinadas a usos residenciales vinculados a la explotación agrícola o ganadera, pero este uso no supone en sí mismo la implantación de una actividad productiva en el medio rural, porque, como establece el artículo 52.3.d) del Reglamento de la ley, la explotación ha de ser preexistente.
} 
ción responda realmente las tipologías edificatorias tradicionales, sino solo que estuviese finalizada con anterioridad a la entrada en vigor de la Ley 19/1975, de 2 de mayo, de reforma sobre el régimen del suelo y ordenación urbana (artículo 63.5, párrafo segundo, del Reglamento de la ley); para un estudio más detallado, cabe remitirse a Raposo Arceo (2019, p. 271 y ss.).

\subsection{La sustitución de la licencia de actividad por una comunicación en todos los municipios}

Entre las medidas de fomento del emprendimiento, que contiene la Ley del emprendimiento y de la competitividad económica de Galicia, destaca por su importancia el nuevo régimen de regulación integrada del ejercicio de actividades económicas, establecido en su capítulo III y desarrollado en el Reglamento único de regulación integrada de actividades económicas y apertura de establecimientos, aprobado por el Decreto 144/2016, de 22 de septiembre. Tal y como señala la Exposición de Motivos de la ley, la Comunidad Autónoma de Galicia, a través de la Ley 1/2010, de 11 de febrero, de modificación de diversas leyes de Galicia, y de su desarrollo reglamentario, ya había efectuado un profundo proceso de adaptación a la Directiva 2006/123/CE del Parlamento Europeo y del Consejo, de 12 de diciembre de 2006, relativa a los servicios en el mercado interior, generalizando la comunicación previa o la declaración responsable como medio de control administrativo en los procedimientos de la Administración autonómica. Sin embargo, faltaba por extender al ámbito de las entidades locales estas nuevas técnicas de intervención administrativa en las actividades económicas ejercidas por los particulares, que facilitan el emprendimiento frente a la anterior exigencia indiscriminada de autorizaciones o licencias administrativas, cuestión de la que se ha ocupado ampliamente la literatura jurídica (entre otros, Aguado Cudolá, 2012, p. 67 y ss.; Fernández Torres, 2011, p. 96 y ss.; González García, 2010, p. 275 y ss.; López Menudo, 2010, p. 115 y ss.).

En ese proceso cabe resaltar, por una parte, la introducción de la comunicación previa al comienzo de actividades comerciales por la Ley 13/2010, de 17 de diciembre, del comercio interior de Galicia, y, por otra parte, la intervención del Estado con normas como la Ley 25/2009, de 22 de diciembre, la Ley 2/2011, de 4 de marzo, de economía sostenible, que modificó la Ley $7 / 1985$, de 2 de abril, reguladora de las bases del régimen local, y la Ley 12/2012, de 26 de diciembre, de medidas urgentes de liberalización del comercio y determinados servicios, analizadas en Socias Camacho (2013, p. 224 y ss.) Asimismo, algunos municipios, sobre todo los de mayor población, ya habían aprobado ordenanzas que introducían la comunicación previa o la declaración responsable para el ejercicio de las actividades económicas, pero otros, en particular los pequeños municipios rurales, no lo habían hecho y seguían exigiendo las tradicionales licencias de actividad, instalación, apertura o funcionamiento, tal y como se expone en Miguez Macho (2018, p. 211 y ss.). Por ello resultaba necesario que la comunidad autónoma estableciese un régimen jurídico único y estable en las actividades sobre las que posee competencia legislativa, pero cuyo control administrativo corresponde a los municipios.

El artículo 23.1 de la Ley del emprendimiento y de la competitividad económica de Galicia proclama que en el ámbito de la comunidad autónoma se suprime con carácter general la necesidad de obtención de licencia municipal de actividad, apertura o funcionamiento para la instalación, implantación o ejercicio de cualquier actividad económica, empresarial, profesional, industrial o comercial. A continuación, el apartado 2 del artículo atribuye a los ayuntamientos la labor de velar por el cumplimiento de los requisitos aplicables según la legislación correspondiente, para lo cual comprobarán, controlarán e inspeccionarán las actividades, aunque es el artículo 28 el que enuncia de manera pormenorizada las potestades municipales en esta materia, que se pueden encontrar desarrolladas con carácter general en Rodríguez Font (2009, p. 291 y ss.).

La sustitución del régimen de licencia por el de comunicación (pues se opta por esta modalidad y no por la declaración responsable) se hace efectiva en el artículo 24. Este precepto señala que, con carácter previo al inicio de la actividad o de la apertura del establecimiento y, en su caso, para el inicio de la obra o instalación que se destine específicamente a una actividad, los interesados presentarán ante el ayuntamiento respectivo una comunicación previa, según la denominación que utilizaba la Ley 
30/1992, de 26 de noviembre, de régimen jurídico de las administraciones públicas y del procedimiento administrativo común (ahora llamada comunicación en la vigente Ley 39/2015, de 1 de octubre, del procedimiento administrativo común de las administraciones públicas). En ella pondrán en conocimiento de la Administración municipal sus datos identificativos y adjuntarán la documentación acreditativa de los requisitos exigibles para el ejercicio de la actividad o para el inicio de la obra o instalación [incluida, de ser necesaria, la correspondiente declaración de impacto o incidencia ambiental, tal y como señalan Fernández Torres (2011, p. 98) y Garrido Juncal (2016, p. 9 y ss.)]. También cabe acompañar, de manera facultativa, el certificado, acta o informe de conformidad emitido por una entidad de certificación de conformidad municipal ${ }^{9}$.

El apartado 2 de este artículo 24 añade que, si para el desarrollo de la actividad fuese precisa la realización de una obra, la documentación anterior se presentará con la comunicación previa recogida en la normativa urbanística o con la solicitud de licencia de obra y, una vez finalizada la obra, se presentará la comunicación previa al inicio de la actividad (hay que entender que ya sin necesidad de aportar documentación adicional). Se adapta, así, al nuevo régimen de intervención la concurrencia de licencias urbanísticas y de actividad o apertura, que tradicionalmente se resolvía estableciendo la prioridad temporal de las segundas sobre las primeras, con objeto de evitar el otorgamiento de licencia para unas obras que luego no pudiesen servir para el fin al que estuviesen destinadas si no se llegase a obtener la licencia de actividad o de apertura.

Por último, el artículo 24.4 de la ley especifica que toda la documentación a la que se refiere el precepto podrá presentarse telemáticamente. En este caso, las comunicaciones y resoluciones de la Administración se tramitarán del mismo modo. Sobre este particular, ha de tenerse en cuenta que en la actualidad las personas jurídicas están obligadas a relacionarse por medios electrónicos con las Administraciones Públicas (artículo 14.2.a) de la Ley 39/2015). Para hacer efectivas estas previsiones, todos los ayuntamientos de Galicia deberán tener en su página web un portal telemático de comunicaciones previas y autorizaciones administrativas.

En cuanto a los efectos de la comunicación de inicio de actividad, el artículo 25 de la Ley del emprendimiento y de la competitividad económica de Galicia señala que la comunicación previa presentada cumpliendo todos los requisitos constituye un acto jurídico del particular que lo habilita para el inicio de la actividad o la apertura del establecimiento y, en su caso, para el inicio de la obra o instalación, y faculta a la Administración pública para verificar la conformidad de los datos que en ella se contienen. A tal efecto, los ayuntamientos deberán establecer y planificar los procedimientos de comunicación necesarios, así como los de verificación posterior del cumplimiento de los requisitos precisos para el ejercicio de la actividad y su control posterior.

\subsection{Las medidas de fomento de implantación de iniciativas empresariales y su incidencia en el medio rural: el régimen de autorización única, con especial referencia a los aprovechamientos forestales}

La Ley de fomento de la implantación de iniciativas empresariales en Galicia contiene un conjunto heterogéneo de medidas vinculadas por el fin común de facilitar la realización de actividades económicas en la Comunidad Autónoma. Algunas de ellas, como las dirigidas a dar salida a la sobreoferta de suelo empresarial, exceden del objeto de este trabajo, pero otras, las de mejora regulatoria que buscan coordinar y simplificar el régimen de intervención administrativa sobre las actividades productivas, sí tienen, en ciertos casos, una incidencia directa sobre el medio rural.

La Ley de fomento de la implantación de iniciativas empresariales coordina en su título II el procedimiento de otorgamiento de la autorización ambiental integrada prevista en el texto refundido de la Ley de prevención y control integrados de la contaminación, aprobado por el Real Decreto legislativo

${ }_{9}^{9}$ Estas entidades se hallan reguladas en la propia Ley del emprendimiento y de la competitividad económica de Galicia y en el Reglamento único de regulación integrada de actividades económicas y apertura de establecimientos; véase Garrido Juncal, (2016, p. 17 y ss.). 
1/2016, de 16 de diciembre [sobre la que cabe remitirse a Chinchilla Marín (2002) y Alonso García (2004)], con el de evaluación de impacto ambiental, en cumplimiento del artículo 14 de la Ley 21/2013, de 9 de diciembre, de evaluación ambiental. En concreto, el procedimiento que se diseña es de aplicación a la autorización de industrias o instalaciones industriales que estén legal o reglamentariamente sometidas a autorización administrativa previa, de conformidad con la Ley 21/1992, de 16 de julio, de industria, lo que incluye las autorizaciones establecidas en la Ley 24/2013, de 26 de diciembre, del sector eléctrico, en la Ley 34/1998, de 7 de octubre, del sector de hidrocarburos, y en el capítulo IV de la Ley orgánica 4/2015, de 30 de marzo, sobre protección de la seguridad ciudadana, en lo referente a las instalaciones químicas para la fabricación de explosivos.

Asimismo, en sus disposiciones finales modifica un conjunto de leyes autonómicas, entre las que hay que resaltar la Ley 8/2009, de 22 de diciembre, por la que se regula el aprovechamiento eólico en Galicia y se crean el canon eólico y el Fondo de Compensación Ambiental; la Ley 3/2008, de 23 de mayo, de ordenación de la minería de Galicia; y la Ley 7/2012, de 28 de junio, de montes de Galicia, con el fin de coordinar los procedimientos de intervención administrativa y de implantar un régimen de autorización única similar al de la autorización ambiental integrada. Por su especial relevancia para el medio rural, interesa detenerse en los cambios que la disposición final décima lleva a cabo en la intervención administrativa sobre los aprovechamientos forestales.

Esos cambios son de dos tipos. En primer lugar, se prevé que, cuando un determinado tipo de aprovechamiento forestal necesita autorización de la Administración autonómica, esa autorización será en todo caso única, atribuyéndose la competencia para su otorgamiento al órgano forestal, e integrándose la intervención de los demás órganos u organismos cuyas competencias se vean afectadas a través de informes preceptivos pero no vinculantes (nueva redacción del artículo 92 de la Ley de montes de Galicia). Si los informes no se emiten en plazo, se entenderán favorables y, en todo caso, si el procedimiento no se resuelve en plazo, se aplicará el silencio administrativo positivo como regla general. En segundo lugar, por medio de un nuevo artículo 92 bis incorporado a la Ley de montes de Galicia, se desarrollan las previsiones de la legislación estatal de montes que someten determinados aprovechamientos forestales a declaración responsable en vez de a autorización administrativa previa, con la consiguiente simplificación de los trámites para su realización. Es más, en supuestos en que la necesidad de autorización administrativa viene motivada por exigencias de la legislación sectorial de competencia autonómica, se prevé la posibilidad de que las consellerías competentes aprueben pliegos de condiciones que permitirían la sustitución de dicha autorización por una declaración responsable de sujeción a esas condiciones (artículo 92.7 de la Ley de montes de Galicia). A todo esto hay que añadir otras medidas de simplificación administrativa, contenidas en la nueva redacción del artículo 94 de la Ley de montes de Galicia ${ }^{10}$.

\section{Las medidas de ordenación de la actividad agraria}

\subsection{De la reestructuración de la propiedad agraria a la recuperación y puesta en valor de la tierra agraria productiva}

La Ley 4/2015, de 17 de julio, de mejora de la estructura territorial agraria de Galicia, que derogó la Ley 10/1985, de 14 de agosto, de concentración parcelaria para Galicia (y también la Ley 11/1983, de 29 de diciembre, de actuación intensiva en las parroquias rurales), constituye un importante hito en la regulación de la reforma de las estructuras agrarias, porque da los primeros pasos para integrar este proceso en un concepto más amplio de desarrollo rural y conseguir, de esta forma, que se pueda con-

\footnotetext{
10 Esta nueva regulación legal ha sido objeto de desarrollo a través del reciente Decreto 73/2020, de 24 de abril, por el que se regulan los aprovechamientos madereros y leñosos, de corcho, de pastos, micológicos y de resinas en montes o terrenos forestales de gestión privada en la Comunidad Autónoma de Galicia, que, además, introduce la obligación general de presentar por medios electrónicos las solicitudes de autorización, las declaraciones responsables y las comunicaciones previstas en ella, así como toda la documentación complementaria.
} 
vertir en un instrumento de lucha contra la despoblación y de dinamización del medio rural. La Exposición de Motivos de la ley destaca que la reforma de las estructuras agrarias ya no se puede entender de manera aislada, como un fin en sí mismo, ya que los actuales modelos de desarrollo rural conciben el medio rural "como un todo en el que, sin duda, la actividad agraria debe ocupar un lugar principal, pero no único ni independiente". Así,

El espacio rural se entiende, desde ese nuevo enfoque, como un conjunto de actividades relacionadas y equilibradas, en el que las funciones productivas deben convivir en armonía con las de defensa del entorno, del paisaje y del patrimonio hacia un objetivo único: la mejora de la calidad de vida de la población en su medio (p. 29139).

Y esta mejora de la calidad de vida incluye, entre otros elementos, la lucha contra el abandono de la tierra, la fijación de la población en el territorio rural y la mejora de los servicios puestos a su disposición.

La necesidad de superar la concepción tradicional de la concentración parcelaria, dirigida a combatir el minifundismo que lastraba la modernización productiva del campo gallego, viene también motivada por el profundo cambio experimentado por este en los últimos años. La propia Exposición de Motivos de la Ley de mejora de la estructura territorial agraria de Galicia resalta que:

La diferencia de situaciones entre el campo gallego de los años 70 del pasado siglo y la actual resulta casi abismal, pasando de una gran cantidad de población dedicada a la actividad agraria a una pérdida de explotaciones y trabajos no absorbidos por otras actividades en el rural y a una drástica reducción en el número de personas trabajadoras y de explotaciones, sin duda hoy mucho más productivas y profesionalizadas, pero que no han sido capaces de absorber el excedente de tierras derivado de la sustitución de la actividad agraria, asistiéndose a un proceso de abandono de tierras agrarias, muchas de ellas con enorme potencial productivo (p. 29139).

Y este abandono de la tierra, entre otras consecuencias negativas, provoca "el cambio del paisaje antropogénico tradicional y el agravamiento de fenómenos negativos como los incendios o la transmisión de plagas".

En definitiva, la Administración y el legislador autonómico gallego han llegado a la conclusión de que de nada sirve reestructurar la propiedad agraria si, una vez realizados los ímprobos esfuerzos administrativos, técnicos y financieros que supone todo proceso de concentración parcelaria, las tierras acaban por quedar abandonadas a causa del envejecimiento y de la despoblación del medio rural. Por ello, la Ley de mejora de la estructura territorial agraria de Galicia menciona entre los objetivos generales de su artículo 2.1 fijar la población en el medio rural y la lucha contra el abandono de la tierra agraria, en directa conexión con las vigentes directrices de ordenación del territorio, y añade que para lograrlo, entre otras medidas, se procurará "movilizar para las explotaciones las fincas con vocación agraria en estado de abandono, haciendo mayor hincapié en aquellas situadas en las zonas de concentración o reestructuración parcelaria" (artículo 2.2.f).

Sin embargo, aunque la Exposición de Motivos afirma que:

El texto legal hace especial hincapié en la movilización de las tierras agrarias en manifiesto estado de abandono mediante la declaración como perímetros abandonados de un conjunto de fincas con vocación agraria, cuando puedan suponer riesgo de incendios forestales o sean objeto de incendios con el consiguiente peligro para las áreas habitadas próximas a las zonas quemadas, o cuando exista demanda de tierra por parte de explotaciones agrarias ya existentes en esas zonas o para nuevas iniciativas de explotaciones agrarias (p. 29143).

en realidad la Ley de mejora de la estructura territorial agraria de Galicia no incorpora, directamente, ninguna medida dirigida a la recuperación y puesta en valor de la tierra agraria productiva. La declara- 
ción de perímetros abandonados a la que se acaba de hacer referencia se introduce, mediante la disposición final primera, en la Ley 6/2011, de 13 de octubre, de movilidad de tierras, de la que se hablará en el siguiente epígrafe, y tampoco lleva aparejada, en realidad, ninguna actuación de movilización de las fincas afectadas, sino más bien de prevención de los incendios forestales.

\subsection{El Banco de Tierras de Galicia}

El Banco de Tierras de Galicia fue creado por la Ley del Parlamento de Galicia 7/2007, de 21 de mayo, de medidas administrativas y tributarias para la conservación de la superficie agraria útil y del Banco de Tierras de Galicia, hoy sustituida por la vigente Ley de movilidad de tierras. Según se desprende del artículo 4.1 de esta ley, el Banco de Tierras es un instrumento similar a un registro jurídico-administrativo, pero destinado específicamente a promover la movilización de la tierra agraria productiva mediante la actividad de mediación que desempeña su entidad gestora, en la actualidad la Axencia Galega de Desenvolvemento Rural (Agader). Así, su principal objetivo es poner en contacto a las personas titulares de fincas agrarias que no pueden o no desean cultivarlas con aquellos que demandan tierra para fines agrarios, o para otros fines compatibles con ellos y que se concretan en el artículo 6.1 de la Ley de movilidad de tierras. En la medida en que la movilización de la tierra agraria contribuye a mantener en el medio rural las actividades productivas ligadas a la agricultura, la ganadería y la silvicultura, no cabe duda de que también ayuda a mitigar la despoblación y a dinamizar esas zonas.

Además, la Ley de movilidad de tierras se ocupa en su título VI de las fincas agrarias abandonadas, regulando un procedimiento administrativo para su declaración como tales, lo que implica para los titulares la obligación bien de realizar por lo menos una agricultura de conservación, bien de cederlas temporalmente a otra persona con esa misma carga o bien de incorporarlas al Banco de Tierras de Galicia. Aunque esta declaración puede desembocar en la movilización de la finca afectada, lo que se persigue, sobre todo, es forzar a los titulares a cumplir el deber de conservación del suelo que les impone el artículo 16.1 del texto refundido de la Ley de suelo y rehabilitación urbana, aprobado por el Real Decreto legislativo $7 / 2015$, de 30 de octubre.

En todo caso, dado el enorme número de fincas agrarias abandonadas que hay en la actualidad en Galicia, un procedimiento como el mencionado, que se tiene que tramitar finca por finca, no es operativo para hacer frente por sí solo al fenómeno de manera efectiva, sin que la posibilidad de declaración de perímetros abandonados, introducida por la Ley de mejora de la estructura territorial agraria de Galicia en la de Ley movilidad de tierras, suponga un avance en tal sentido, pues también exige la tramitación de un procedimiento individualizado por cada finca.

\subsection{La introducción de nuevos instrumentos de recuperación y puesta en valor de la tierra agraria productiva}

El Dictamen de la Comisión Especial no Permanente del Parlamento de Galicia de estudio y análisis de las reformas de la política forestal, de prevención y extinción de incendios forestales y del plan forestal de Galicia, aprobado el 31 de julio de 2018, al que se ha hecho referencia en la Introducción, contiene algunas propuestas de nuevos instrumentos de recuperación y puesta en valor de la tierra agraria productiva. Así, en su apartado 82, recomienda impulsar el establecimiento de entidades similares a las juntas de compensación urbanísticas para facilitar la gestión conjunta de las tierras mediante su integración obligatoria, siempre que dichas entidades sean promovidas por los titulares de la mayoría de la superficie del ámbito de actuación. Sin embargo, las juntas de compensación urbanística no parecen un buen modelo para trasladar al ámbito de la gestión agraria, ya que, aparte de las evidentes diferencias entre la gestión urbanística y la agraria, la experiencia demuestra que tales entidades con frecuencia fracasan cuando la propiedad está muy dividida, que es justo lo que sucede en el medio rural gallego, por no hablar del problema que supondría la integración en estas iniciativas de las fincas de 
propietario desconocido. Sería más adecuado fomentar la constitución de entidades de gestión conjunta de la tierra agraria, de carácter asociativo y voluntario, extendiendo el modelo de las sociedades forestales al ámbito agropecuario, pero superando el carácter obligadamente mercantil que estas tienen en la legislación estatal que las regula (disposición adicional quinta de la Ley 43/2003, de 21 de noviembre, de montes).

Otra recomendación, que se recoge en el apartado 83 del Dictamen, consiste en la creación de la figura de los polígonos agrícolas y forestales, vinculados a proyectos agroforestales viables, dentro de una ordenación integral del territorio rural de Galicia que se tendría que desarrollar con carácter previo. Esta propuesta se liga expresamente a las actuaciones de fijación de población en el medio rural, por lo que se tendría que dar preferencia a la participación en los proyectos agroforestales de los habitantes de la zona delimitada. La Agencia Galega de Desenvolvemento Rural asumiría el protagonismo tanto en la delimitación de los polígonos, atendiendo a la demanda de empresas agroganaderas y forestales o a la iniciativa de nuevos emprendedores que necesiten tierras para llevar a cabo proyectos viables, como en la mediación entre estos promotores y los titulares de las tierras para su venta o arrendamiento, incluyendo la investigación de la propiedad en los casos en que no esté debidamente determinada.

La denominación de polígonos está de nuevo tomada del ámbito urbanístico, pero, más allá de estas dudosas analogías, la clave del éxito de la propuesta se halla, sin duda, en la existencia de proyectos de explotación agraria concretos y viables que garanticen que las tierras afectadas por la actuación vayan a ser trabajadas, con reestructuración de la propiedad o sin ella. Por eso, en un apartado anterior del Dictamen, el 81, se recomienda también el desarrollo, a través de la Agencia Gallega de Desenvolvemento Rural y en colaboración con los ayuntamientos y otros actores públicos y privados, de proyectos piloto de movilización de tierras agrarias, cuando exista una demanda efectiva para el desarrollo de iniciativas productivas.

Con esta finalidad, el artículo 21.dos de la Ley 3/2018, de 26 de diciembre, de medidas fiscales y administrativas, ha introducido un nuevo artículo 47 bis en la Ley de movilidad de tierras que regula los denominados "proyectos de movilización de tierras". El precepto habilita a la Agencia Galega de Desenvolvemento Rural para identificar y declarar como zonas de actuación integral para el desarrollo de estos proyectos áreas mayoritariamente abandonadas (lo que implica que dentro de su perímetro podrá haber fincas en explotación que queden al margen del proyecto de movilización) que alcancen, en principio, una superficie igual o superior a las diez hectáreas, aunque se admite, excepcionalmente, que puedan tener una extensión inferior, en todo caso superior a tres hectáreas. La ejecución de estos proyectos, siempre atribuida a la Agencia, implica la incorporación de las fincas abandonadas o deficientemente cultivadas al Banco de Tierras (salvo que se trate de bosques situados en terrenos comunales, que no se incorporan al banco) para su inmediata cesión a aquellos que participen en el proyecto, por mutuo acuerdo entre las partes, con objeto de ponerlas en explotación.

En principio, la participación de los titulares de las fincas en el proyecto de movilización es voluntaria, pero negarse a hacerlo supone la obligación de mantenerlas en explotación conforme a las buenas prácticas agroforestales. En caso contrario, se iniciará el procedimiento para declararlas en estado de abandono, con lo que acabarían incorporándose de manera forzosa al Banco de Tierras y, consecuentemente, al proyecto de movilización. De esta forma, la eventual oposición o resistencia de los titulares de fincas abandonadas o deficientemente cultivadas a integrarlas en estos proyectos no frenaría su ejecución, sin perjuicio de que, si aquellos deciden ponerlas en explotación por sí mismos, no se verían obligados a cederlas a terceros, porque el objetivo de evitar el abandono se habría conseguido.

Otra dificultad para la ejecución de estos proyectos deriva de la enorme cantidad de fincas de propietario desconocido que hay en el medio rural gallego, muchas veces pertenecientes pro indiviso a comunidades hereditarias de las que resulta muy difícil seguir el rastro. Para solventarla, el artículo 47 bis de la Ley de movilidad de tierras permite la integración cautelar en los proyectos de explotación de las fincas abandonadas que se hallen en proceso de investigación de la titularidad, o respecto de las 
que resulte imposible identificar al propietario, o que pertenezcan pro indiviso a varias personas entre las que no exista acuerdo sobre el destino que se les deba dar o, por último, que estén declaradas como de propietario desconocido. La integración cautelar se hace con la lógica reserva de que se dejan a salvo los derechos de los titulares, que podrán ser ejercitados por estos una vez determinada, en su caso, la propiedad de las fincas.

A estas previsiones se acaba de unir el programa de "aldeas modelo" del nuevo artículo 47 ter de la Ley de movilidad de tierras, incorporado a esta por el artículo 18.dos de la Ley 7/2019, de 23 de diciembre, de medidas fiscales y administrativas. Según la Exposición de Motivos de la ley, el programa:

Está diseñado como un sistema para recuperar y poner en valor las tierras circundantes a núcleos de población, incluyendo total o parcialmente sus fajas secundarias de protección de biomasa, con la finalidad de recuperar la capacidad agronómica del perímetro del proyecto, su rehabilitación y recuperación arquitectónica y urbanística y la promoción del empleo y la dinamización socioeconómica (p. 12107).

\section{Conclusiones}

Este estudio muestra cómo la política de mejora regulatoria emprendida por la Comunidad Autónoma de Galicia a lo largo de la última década puede ser un factor que contribuya a mitigar la despoblación del medido rural, al facilitar la implantación de actividades productivas en las zonas en riesgo de despoblación y contribuir, así, a la fijación de población en ellas. Hay ámbitos en los que los avances producidos son sustanciales, como el del régimen urbanístico y de intervención administrativa en las actividades económicas, apreciablemente simplificado por las últimas modificaciones legislativas, aunque todavía subsistan aspectos que precisarían de ulteriores mejoras (en particular, la tramitación de los procedimientos de evaluación ambiental, que en la actualidad es uno de los elementos que más retrasa la ejecución de los proyectos empresariales sujetos a esta forma de intervención). Por lo demás, no debe desconocerse que la implantación de actividades productivas en el medio rural no solo depende de la existencia de un marco regulatorio favorable, sino también de la disponibilidad de las infraestructuras y servicios necesarios, entre los que, en la actualidad, adquieren especial relevancia los ligados a la sociedad y a la economía digitales, tal y como se expone en Martínez Puche (2019).

Otro importante desafío para Galicia es el que representa el abandono de la tierra agraria productiva. La experiencia práctica en el funcionamiento del Banco de Tierras de Galicia y en la aplicación de la vigente Ley de movilidad de tierras ha aconsejado la previsión de nuevos instrumentos de recuperación y puesta en valor de las tierras en estado de abandono o de cultivo deficiente, en los que la iniciativa de la Administración pasa a ser determinante y, sobre todo, permite actuar conjuntamente sobre extensiones de terreno de una cierta entidad para hacer viables proyectos de explotación agraria de envergadura. De esta manera, probablemente, pueda superarse el problema que supone tener que esperar a la decisión voluntaria de los titulares de las fincas de incorporarlas al Banco de Tierras ${ }^{11}$, que solo se exceptuaba en los supuestos de declaración de fincas en estado de abandono. Asimismo, también se logrará superar la dificultad que presenta, para los sujetos o entidades interesadas en emprender proyectos de explotación agraria, el acceso a extensiones de terreno suficiente para llevarlos a cabo, a causa de la fragmentación que sigue caracterizando a la propiedad agraria en Galicia y por la falta de determinación de la titularidad de muchas tierras.

11 Según los datos publicados en la propia página web de la Agencia Galega de Desenvolvemento Rural (https://agader.xunta.gal/es/banco-de-tierras/datos-principales/), actualizados a 15 de agosto de 2019, están incorporadas al Banco de Tierras un total de 10.570 fincas (de unos once millones de fincas rústicas que hay en Galicia), que representan una superficie de 5.461,91 hectáreas (sobre casi tres millones de hectáreas de superficie rústica, aunque dos millones lo son de superficie forestal). Última consulta el 5 de mayo de 2020. 


\section{Bibliografía}

Aguado Cudolá, V. (2012). La libertad de establecimiento de los prestadores de servicios: autorización, declaración responsable, comunicación previa y silencio positivo. En V. Aguado Cudolá y B. Noguera de la Muela (Eds.), Impacto de la Directiva de Servicios en las Administraciones Públicas: aspectos generales y sectoriales (pp. 67-90). Barcelona: Atelier.

Alonso García, M. C. (2004). Autorización ambiental integrada. Revista Aragonesa de Administración Pública, extra 7, 81-97.

Bustillo Bolado, R. O., y Menéndez Sebastián, E. M. (2005). Desarrollo rural y gestión sostenible del monte. Madrid: Iustel.

Chinchilla Marín, M. C. (2002). La autorización ambiental integrada: la Ley 16/2002, de 1 de julio, de prevención y control integrados de la contaminación. Administración de Andalucía: Revista Andaluza de Administración Pública, 47, 43-72.

Comunidad Europea. (2006). Directiva 2006/123/CE del Parlamento Europeo y del Consejo, de 12 de diciembre de 2006, relativa a los servicios en el mercado interior. Diario Oficial de la Unión Europea, L 376, de 27 de diciembre de 2006, 36-68.

Recuperado de: https://eur-lex.europa.eu/legal-content/ES/TXT/PDF/?uri=CELEX:32006L0123\&from=EN

Decreto 19/2011, de 10 de febrero, por el que se aprueban definitivamente las directrices de ordenación del territorio. Diario Oficial de Galicia, 36, de 22 de febrero de 2011, 2893-2921.

Recuperado de: https://xeg.xunta.gal/sites/default/files/documentos/Decreto\%2019 2011.pdf

Decreto 20/2011, de 10 de febrero, por el que se aprueba definitivamente el Plan de Ordenación del Litoral de Galicia. Diario Oficial de Galicia, 37, de 23 de febrero de 2011, 2974-3009.

Recuperado de: https://xeg.xunta.gal/sites/default/files/documentos/Decreto\%2020\%202011.pdf

Decreto 143/2016, de 22 de septiembre, por el que se aprueba el Reglamento de la Ley 2/2016, de 10 de febrero, del suelo de Galicia. Diario Oficial de Galicia, 213, de 9 de noviembre de 2016, 49305-49721. Recuperado de: https://www.xunta.gal/dog/Publicados/2016/20161109/AnuncioG0422-281016-0013 es.pdf

Decreto 144/2016, de 22 de septiembre, por el que se aprueba el Reglamento único de regulación integrada de actividades económicas y apertura de establecimientos. Diario Oficial de Galicia, 213, de 9 de noviembre de 2016, 49722-49802. Recuperado de: https://www.xunta.gal/dog/Publicados/2016/20161109/AnuncioG0424-281016-0016 es.pdf

Decreto 83/2018, de 26 de julio, por el que se aprueba el Plan básico autonómico de Galicia. Diario Oficial de Galicia, 162, de 27 de agosto de 2018, 39198-39319. Recuperado de:

https://www.xunta.gal/dog/Publicados/2018/20180827/AnuncioG0422-090818-0001 es.pdf

Decreto 73/2020, de 24 de abril, por el que se regulan los aprovechamientos madereros y leñosos, de corcho, de pastos, micológicos y de resinas en montes o terrenos forestales de gestión privada en la Comunidad Autónoma de Galicia. Diario Oficial de Galicia, 97, de 20 de mayo de 2020, 20716-20807. Recuperado de: https://www.xunta.gal/dog/Publicados/2020/20200520/AnuncioG0426-080520-0001 es.pdf

Fernández Torres, J. R. (2011). Regímenes de intervención administrativa: autorización, comunicación previa y declaración responsable. Revista Catalana de Dret Públic, 42, 85-114. Recuperado de:

http://revistes.eapc.gencat.cat/index.php/rcdp/article/view/2216

Garrido Juncal, A. (2016). Las transformaciones del régimen de intervención administrativa en el procedimiento de evaluación de incidencia ambiental de actividades. El supuesto particular de la legislación gallega. Revista Catalana de Dret Ambiental, VII(1), 1-28. Recuperado de: https://www.raco.cat/index.php/rcda/article/view/314953

González García, J. V. (2010). Autorizaciones, comunicaciones previas y declaraciones responsables en la transposición de la Directiva de Servicios. Revista d'Estudis Autonòmics i Federals, 11, 255-293. Recuperado de: https://www.globalpoliticsandlaw.net/articulos/autorizaciones-comunicaciones-previas-y-declaracionesresponsables-en-la-transposicion-de-la-directiva-de-servicios/

Ley 19/1975, de 2 de mayo, de reforma de la Ley sobre régimen del suelo y ordenación urbana. Boletín Oficial del Estado, 107, de 5 de mayo de 1975, 9427-9448.

Recuperado de: https://www.boe.es/boe/dias/1975/05/05/pdfs/A09427-09448.pdf

Ley 11/1983, de 29 de diciembre, de actuación intensiva en las parroquias rurales. Legislación consolidada. Comunidad Autónoma de Galicia. Diario Oficial de Galicia, 22, de 2 de febrero de 1984 y Boletín Oficial del Estado, 13, de 15 de enero de 1985. Referencia: BOE-A-1985-877.

Recuperado de: https://www.boe.es/buscar/pdf/1985/BOE-A-1985-877-consolidado.pdf 
Ley 7/1985, de 2 de abril, reguladora de las bases del régimen local. Legislación consolidada. Jefatura del Estado. Boletín Oficial del Estado, 80, de 3 de abril de 1985. Referencia: BOE-A-1985-5392.

Recuperado de: https://www.boe.es/buscar/pdf/1985/BOE-A-1985-5392-consolidado.pdf

Ley 10/1985, de 14 de agosto, de concentración parcelaria para Galicia. Legislación consolidada. Comunidad Autónoma de Galicia. Diario Oficial de Galicia, 160, de 22 de agosto de 1985 y Boletín Oficial del Estado, 275, de 16 de noviembre de 1985. Referencia: BOE-A-1985-23695.

Recuperado de: https://www.boe.es/buscar/pdf/1985/BOE-A-1985-23695-consolidado.pdf

Ley 21/1992, de 16 de julio, de industria. Jefatura del Estado. Boletín Oficial del Estado, 176, de 23 de julio de 1992. Referencia: BOE-A-1992-17363.

Recuperado de: https://www.boe.es/buscar/pdf/1992/BOE-A-1992-17363-consolidado.pdf

Ley 30/1992, de 26 de noviembre, de régimen jurídico de las Administraciones Públicas y del procedimiento administrativo común. Legislación consolidada. Jefatura del Estado. Boletín Oficial del Estado, 285, de 27 de noviembre de 1992. Referencia: BOE-A-1992-26318.

Recuperado de: https://www.boe.es/buscar/pdf/1992/BOE-A-1992-26318-consolidado.pdf

Ley 34/1998, de 7 de octubre, del sector de hidrocarburos. Legislación consolidada. Jefatura del Estado. Boletín Oficial del Estado, 241, de 8 de octubre de 1998. Referencia: BOE-A-1998-23284.

Recuperado de: https://www.boe.es/buscar/pdf/1998/BOE-A-1998-23284-consolidado.pdf

Ley 43/2003, de 21 de noviembre, de montes. Legislación consolidada. Jefatura del Estado. Boletín Oficial del Estado, 280, de 22 de noviembre de 2003. Referencia: BOE-A-2003-21339. Última modificación: 21 de julio de 2015. Recuperado de: https://www.boe.es/buscar/pdf/2003/BOE-A-2003-21339-consolidado.pdf

Ley 7/2007, de 21 de mayo, de medidas administrativas y tributarias para la conservación de la superficie agraria útil y del Banco de Tierras de Galicia. Comunidad Autónoma de Galicia. Boletín Oficial del Estado, 171, de 18 de julio de 2007, 31238-31251.

Recuperado de: https://www.boe.es/eli/es-ga/l/2007/05/21/7/dof/spa/pdf

Ley 3/2008, de 23 de mayo, de ordenación de la minería de Galicia. Legislación consolidada. Comunidad Autónoma de Galicia. Diario Oficial de Galicia, 109, de 6 de junio de 2008 y Boletín Oficial del Estado, 165, de 9 de julio de 2008. Referencia: BOE-A-2008-11587. Recuperado de: https://www.boe.es/buscar/pdf/2008/BOEA-2008-11587-consolidado.pdf

Ley 8/2009, de 22 de diciembre, por la que se regula el aprovechamiento eólico en Galicia y se crean el canon eólico y el Fondo de Compensación Ambiental. Legislación consolidada. Comunidad Autónoma de Galicia. Diario Oficial de Galicia, 252, de 29 de diciembre de 2009 y Boletín Oficial del Estado, 30, de 4 de febrero de 2010. Referencia: BOE-A-2010-1708.

Recuperado de: https://www.boe.es/buscar/pdf/2010/BOE-A-2010-1708-consolidado.pdf

Ley 25/2009, de 22 de diciembre, de modificación de diversas leyes para su adaptación a la Ley sobre el libre acceso a las actividades de servicios y su ejercicio. Legislación consolidada. Jefatura del Estado. Boletín Oficial del Estado, 308, de 23 de diciembre de 2009. Referencia: BOE-A-2009-20725.

Recuperado de: https://www.boe.es/buscar/pdf/2009/BOE-A-2009-20725-consolidado.pdf

Ley 1/2010, de 11 de febrero, de modificación de diversas leyes de Galicia para su adaptación a la Directiva 2006/123/CE, del Parlamento Europeo y del Consejo, de 12 de diciembre de 2006, relativa a los servicios en el mercado interior. Comunidad Autónoma de Galicia. Boletín Oficial del Estado, 86, de 9 de abril de 2010, 32123-32154. Recuperado de: https://www.boe.es/boe/dias/2010/04/09/pdfs/BOE-A-2010-5665.pdf

Ley 13/2010, de 17 de diciembre, del comercio interior de Galicia. Legislación consolidada. Comunidad Autónoma de Galicia. Diario Oficial de Galicia, 249, de 29 de diciembre de 2010 y Boletín Oficial del Estado, 25, de 29 de enero de 2011. Referencia: BOE-A-2011-1649.

Recuperado de: https://www.boe.es/buscar/act.php?id=BOE-A-2011-1649

Ley 2/2011, de 4 de marzo, de economía sostenible. Legislación consolidada. Jefatura del Estado. Boletín Oficial del Estado, 55, de 5 de marzo de 2011. Referencia: BOE-A-2011-4117.

Recuperado de: https://www.boe.es/buscar/pdf/2011/BOE-A-2011-4117-consolidado.pdf

Ley 6/2011, de 13 de octubre, de movilidad de tierras. Legislación consolidada. Comunidad Autónoma de Galicia. Diario Oficial de Galicia, 205, de 26 de octubre de 2011 y Boletín Oficial del Estado, 272, de 11 de noviembre de 2011. Referencia: BOE-A-2011-17718. Recuperado de: https://www.boe.es/buscar/pdf/2011/BOE-A-201117718-consolidado.pdf

Ley 7/2012, de 28 de junio, de montes de Galicia. Legislación consolidada. Comunidad Autónoma de Galicia. Diario Oficial de Galicia, 140, de 23 de julio de 2012 y Boletín Oficial del Estado, 217, de 8 de septiembre de 2012. Referencia: BOE-A-2012-11414. Recuperado de: https://www.boe.es/buscar/pdf/2012/BOE-A-2012-11414consolidado.pdf 
Ley 12/2012, de 26 de diciembre, de medidas urgentes de liberalización del comercio y determinados servicios. Legislación consolidada. Jefatura del Estado. Boletín Oficial del Estado, 311, de 27 de diciembre de 2012. Referencia: BOE-A-2012-1559.

Recuperado de: https://www.boe.es/buscar/pdf/2012/BOE-A-2012-15595-consolidado.pdf

Ley 9/2013, de 19 de diciembre, del emprendimiento y de la competitividad económica de Galicia. Legislación consolidada. Comunidad Autónoma de Galicia. Diario Oficial de Galicia, 247, de 27 de diciembre de 2013 y Boletín Oficial del Estado, 25, de 29 de enero de 2014. Referencia: BOE-A-2014-883.

Recuperado de: https://www.boe.es/buscar/pdf/2014/BOE-A-2014-883-consolidado.pdf

Ley 21/2013, de 9 de diciembre, de evaluación ambiental. Legislación consolidada. Jefatura del Estado. Boletín Oficial del Estado, 296, de 11 de diciembre de 2013. Referencia: BOE-A-2013-12913.

Recuperado de: https://www.boe.es/buscar/pdf/2013/BOE-A-2013-12913-consolidado.pdf

Ley 24/2013, de 26 de diciembre, del sector eléctrico. Legislación consolidada. Jefatura del Estado. Boletín Oficial del Estado, 310, de 27 de diciembre de 2013. Referencia: BOE-A-2013-13645.

Recuperado de: https://www.boe.es/buscar/pdf/2013/BOE-A-2013-13645-consolidado.pdf

Ley 4/2015, de 17 de julio, de mejora de la estructura territorial agraria de Galicia. Legislación consolidada. Comunidad Autónoma de Galicia. Diario Oficial de Galicia, 131, de 14 de julio de 2015 y Boletín Oficial del Estado, 196, de 17 de agosto de 2015. Referencia: BOE-A-2015-9230.

Recuperado de: https://www.boe.es/buscar/pdf/2015/BOE-A-2015-9230-consolidado.pdf

Ley orgánica 4/2015, de 30 de marzo, sobre protección de la seguridad ciudadana. Legislación consolidada. Jefatura del Estado. Boletín Oficial del Estado, 77, de 31 de marzo de 2015. Referencia: BOE-A-2015-3442. Recuperado de: https://www.boe.es/buscar/pdf/2015/BOE-A-2015-3442-consolidado.pdf

Ley 39/2015, de 1 de octubre, del procedimiento administrativo común de las Administraciones Públicas. Legislación consolidada. Jefatura del Estado. Boletín Oficial del Estado, 236, de 2 de octubre de 2015. Referencia: BOE-A-2015-10565.

Recuperado de: https://www.boe.es/buscar/pdf/2015/BOE-A-2015-10565-consolidado.pdf

Ley 2/2016, de 10 de febrero, del suelo de Galicia. Legislación consolidada. Comunidad Autónoma de Galicia. Diario Oficial de Galicia, 34, de 19 de febrero de 2016 y Boletín Oficial del Estado, 81, de 4 de abril de 2016. Referencia: BOE-A-2016-3191.

Recuperado de: https://www.boe.es/buscar/pdf/2016/BOE-A-2016-3191-consolidado.pdf

Ley 5/2017, de 19 de octubre, de fomento de la implantación de iniciativas empresariales en Galicia. Legislación consolidada. Comunidad Autónoma de Galicia. Diario Oficial de Galicia, 203, de 25 de octubre de 2017 y Boletín Oficial del Estado, 273, de 10 de noviembre de 2017. Referencia: BOE-A-2017-12949. Recuperado de: https://www.boe.es/buscar/pdf/2017/BOE-A-2017-12949-consolidado.pdf

Ley 3/2018, de 26 de diciembre, de medidas fiscales y administrativas. Legislación consolidada. Comunidad Autónoma de Galicia. Diario Oficial de Galicia, 247, de 28 de diciembre de 2018 y Boletín Oficial del Estado, 68, de 20 de marzo de 2019. Referencia: BOE-A-2019-3997.

Recuperado de: https://www.boe.es/buscar/pdf/2019/BOE-A-2019-3997-consolidado.pdf

Ley 7/2019, de 23 de diciembre, de medidas fiscales y administrativas. Comunidad Autónoma de Galicia. Boletín Oficial del Estado, 33, de 7 de febrero de 2020, 12104-12191. Recuperado de: https://www.boe.es/eli/esga/l/2019/12/23/7/dof/spa/pdf

López Menudo, F. (2010). La transposición de la Directiva de Servicios y la modificación de la Ley 30/1992: el régimen de la declaración responsable y de la comunicación previa. Revista Española de la Función Consultiva, 14, 111-149. Recuperado de:

https://idus.us.es/bitstream/handle/11441/28828/La\%20transposici\%c3\%b3n\%20de\%20la\%20Directiva \%20de\%20Servicios.pdf?sequence=1\&isAllowed $=\mathrm{y}$

Martínez Puche, A. (2019). Territorios inteligentes y desarrollo local. Del concepto al precepto. En M.T. Cantó López (Ed.), Los territorios rurales inteligentes: administración e integración social. Cizur Menor (Navarra): Thomson Reuters-Aranzadi.

Miguez Macho, L. (2018). El impacto de la Directiva de Servicios en el Ordenamiento jurídico español. En D. Santiago Iglesias y M. Bertel (Eds.), Libre prestación de servicios y Administración local. Análisis comparativo de la transposición de la Directiva Bolkenstein diez años después (pp. 189-224). Cizur Menor (Navarra): Thomson Reuters-Aranzadi.

Miguez Macho, L. (2019). Clases de planes y sus procedimientos de tramitación y aprobación. En F. J. Sanz Larruga y A. Fernández Carballal (Eds.), Derecho urbanístico de Galicia. En homenaje al Profesor Meilán Gil (pp. 325-389). Valencia: Tirant Lo Blanch. 
Raposo Arceo, J. (2019). Suelo rústico en la nueva normativa del suelo de Galicia: un nuevo enfoque regulatorio. En F.J. Sanz Larruga y A. Fernández Carballal (Eds.), Derecho urbanístico de Galicia. En homenaje al Profesor Meilán Gil (pp. 233-291). Valencia: Tirant Lo Blanch.

Real Decreto Legislativo 7/2015, de 30 de octubre, por el que se aprueba la Ley de suelo y rehabilitación urbana. Boletín Oficial del Estado, 261, de 31 de octubre de 2015, 103232-103290.

Recuperado de: https://www.boe.es/boe/dias/2015/10/31/pdfs/BOE-A-2015-11723.pdf

Real Decreto Legislativo 1/2016, de 16 de diciembre, por el que se aprueba el texto refundido de la Ley de prevención y control integrados de la contaminación. Boletín Oficial del Estado, 316, de 31 de diciembre de 2016, 91806-91842. Recuperado de: https://www.boe.es/eli/es/rdlg/2016/12/16/1/dof/spa/pdf

Rodríguez Font, M. (2009). Declaración responsable y comunicación previa: su operatividad en el ámbito local. Anuario del Gobierno Local, 1, pp. 261-300. Recuperado de: http://repositorio.gobiernolocal.es/xmlui/bitstream/handle/10873/641/RODRIGUEZ_p261300Ranuario20 09 completo-6.pdf?sequence=1\&isAllowed=y

Socias Camacho, J. M. (2013). El nuevo modelo de intervención administrativa en el ámbito local. Revista Aragonesa de Administración Pública, 41-42, 207-240. Recuperado de: https://dialnet.unirioja.es/servlet/articulo?codigo=4486349

Valenzuela Rodríguez, M. J. (2019). Suelo de núcleo rural. En F.J. Sanz Larruga y A. Fernández Carballal (Eds.), Derecho urbanístico de Galicia. En homenaje al Profesor Meilán Gil (pp. 207-231). Valencia: Tirant Lo Blanch. 